\title{
Growth and Characterization of Nanostructured TiCrN Films Prepared by DC Magnetron Cosputtering
}

\author{
Chutima Paksunchai, ${ }^{1}$ Somyod Denchitcharoen, ${ }^{1}$ \\ Surasing Chaiyakun, ${ }^{2,3}$ and Pichet Limsuwan ${ }^{1,3}$ \\ ${ }^{1}$ Department of Physics, Faculty of Science, King Mongkut's University of Technology Thonburi, Bangkok 10140, Thailand \\ ${ }^{2}$ Vacuum Technology and Thin Film Research Laboratory, Department of Physics, Faculty of Science, Burapha University, \\ Chonburi 20131, Thailand \\ ${ }^{3}$ Thailand Center of Excellence in Physics, CHE, Ministry of Education, Bangkok 10400, Thailand
}

Correspondence should be addressed to Chutima Paksunchai; chutima.sci@gmail.com

and Pichet Limsuwan; opticslaser@yahoo.com

Received 4 April 2014; Accepted 25 June 2014; Published 14 July 2014

Academic Editor: Margarida Amaral

Copyright ( 2014 Chutima Paksunchai et al. This is an open access article distributed under the Creative Commons Attribution License, which permits unrestricted use, distribution, and reproduction in any medium, provided the original work is properly cited.

\begin{abstract}
Nanostructured $\mathrm{TiCrN}$ films were grown on $\mathrm{Si}(100)$ wafers by reactive DC unbalanced magnetron cosputtering technique without external heating and voltage biasing to the substrates. The effects of Ti sputtering current on the chemical composition, chemical state, electronic structure, crystal structure, and morphology of the TiCrN films were characterized by X-ray photoelectron spectroscopy (XPS), X-ray diffraction (XRD), atomic force microscopy (AFM), and field emission scanning electron microscopy (FE-SEM), respectively. The results showed that all prepared films were formed as an understoichiometric (Ti, Cr)N solid solution with the fcc B1 type phase. The films exhibited a nanostructure with a crystallite size of less than $14 \mathrm{~nm}$. The deconvolution of XPS spectra revealed the chemical bonding between $\mathrm{Ti}, \mathrm{Cr}, \mathrm{N}$, and $\mathrm{O}$ elements. The addition of Ti contents led to the decrease of valence electrons filled in the $\mathrm{d}$ conduction bands which result in the change of binding energy of electrons in core levels. The roughness of the films was found to increase with increasing $I_{\mathrm{Ti}}$. The cross-sectional morphology of the films showed columnar structure with dome tops.
\end{abstract}

\section{Introduction}

In the past decades, binary nitride films such as TiN [1], $\mathrm{CrN}[2]$, and $\mathrm{ZrN}[3]$ have been widely used in industries as hard coatings for wear and corrosion protection due to their high hardness, chemical stability, good wear resistance, and nice color. However, in spite of their excellent properties, the films still show inadequate properties for some applications. For example, the mechanical properties of $\mathrm{TiN}$ and $\mathrm{CrN}$ are degraded by oxidation during machining process at high temperature above $600^{\circ} \mathrm{C}$ and $800^{\circ} \mathrm{C}$ [4], respectively. Consequently, in order to overcome this problem, the new coating materials with improved properties are needed.

Recently, the ternary nitride films such as $\mathrm{TiCrN} \mathrm{[5-10],}$ CrZrN [11], TiAlN [12], and CrAlN [13] are greatly interesting to enhance the mechanical and chemical properties at high temperature. TiCrN, especially, has been attracting more attention owing to high hardness, high temperature oxidation resistance, and low friction coefficient [5-10, 14-20]. Actually, it is well known that the film properties strongly depend on the microstructure of the films such as phase, grain, and defect structure which relate to the deposition parameters. In general, $\mathrm{TiCrN}$ films can be prepared by different techniques such as reactive magnetron sputtering, ion beam assisted deposition, cathodic arc, and electron beam evaporation. Among these methods, the reactive magnetron sputtering is one of the most widely used techniques to prepare the films with large area uniformity and strong adhesion.

Although there are many research works regarding the structural and mechanical properties of TiCrN films, few studies reported the influence of the deposition parameters on chemical state and electronic structure of the TiCrN films. 
The purpose of this study is to prepare nanostructured $\mathrm{TiCrN}$ films by reactive DC unbalanced magnetron cosputtering without substrate bias voltage and external heating. The effects of sputtering current of Ti target on chemical composition, chemical state, electronic structure, and structural and morphological properties of TiCrN films were investigated.

\section{Experimental Details}

2.1. Films Preparation. TiCrN films were prepared by a home-built reactive DC unbalanced magnetron cosputtering system as shown in Figure 1. Metallic titanium (99.97\%) and chromium (99.95\%) both with a diameter of 3 inches and a thickness of 0.125 inch were used as the sputtering targets. The substrate was Si (100) wafer and it was placed vertically on the holder at the center of the chamber. The distance from the substrate to each target was $13 \mathrm{~cm}$. The base pressure of the vacuum chamber was $5 \times 10^{-5}$ mbar. Pure $\operatorname{Ar}(99.99 \%)$ and $\mathrm{N}_{2}$ (99.99\%) were used as the sputtering and reactive gases, respectively. The flow rates of $\mathrm{Ar}$ and $\mathrm{N}_{2}$ were fixed at 3.0 and $6.0 \mathrm{sccm}$, respectively, regardless of total pressure. Prior to the deposition, the substrate was ultrasonically cleaned in acetone and then in isopropyl alcohol for $20 \mathrm{~min}$ in each step and finally dried with $\mathrm{N}_{2}$ gas. The targets were sputter-cleaned by Ar gas for $5 \mathrm{~min}$ to remove the oxides and impurities on the target surface. During deposition, the Ti and Cr targets were supplied by two independent power supplies. The films were prepared under various conditions of $\mathrm{Ti}$ sputtering current $\left(I_{\mathrm{Ti}}\right)$ in order to grow films with different Ti content. The details of deposition conditions used in this study are presented in Table 1.

2.2. Characterization. The chemical composition and chemical states of TiCrN films were investigated by X-ray photoelectron spectroscopy (XPS: Kratos, AXIS Ultra DLD). The base pressure in the XPS analysis chamber was about $5 \times$ $10^{-9}$ torr. The samples were excited with X-ray hybrid mode using a monochromatic $\mathrm{Al} \mathrm{K \alpha}$ radiation at $1486.6 \mathrm{eV}$ and the photoelectrons were detected with a hemispherical analyzer. Before analysis, the films were cleaned by in-situ $\mathrm{Ar}^{+}$ion bombardment with an ion energy of $4000 \mathrm{eV}$ and an ion current of $50 \mu \mathrm{A}$ on an area of about $2 \times 2 \mathrm{~mm}^{2}$ for $180 \mathrm{~s}$ to remove the contaminants. After sputter etching, XPS valence band spectra were performed over the binding energy range $-4<E_{B} \leq 20 \mathrm{eV}$ and core level spectra were recorded with an emphasis on the peaks associated with Ti 2 p, $\mathrm{Cr} 2 \mathrm{p}, \mathrm{N} 1 \mathrm{~s}$, and $\mathrm{O}$ 1s. The quantitative analysis of the films was determined from the peak area measurements.

The structural analysis of the TiCrN films was characterized by X-ray diffraction (XRD: Rigaku, Rint 2000) using a monochromatic $\mathrm{Cu} \mathrm{K} \alpha$ radiation $(\lambda=0.154 \mathrm{~nm})$ and generator settings of $40 \mathrm{kV}$ and $40 \mathrm{~mA}$. The XRD patterns were acquired in a continuous mode, scanning speed of $2^{\circ} / \mathrm{min}$ and the grazing incidence angle of $3^{\circ}$. The phases of the films were determined using Bragg's law and interplanar spacing equation and then compared with the Joint Committee on Powder Diffraction Standard (JCPDS) files. The surface and cross-sectional morphologies were examined by atomic force

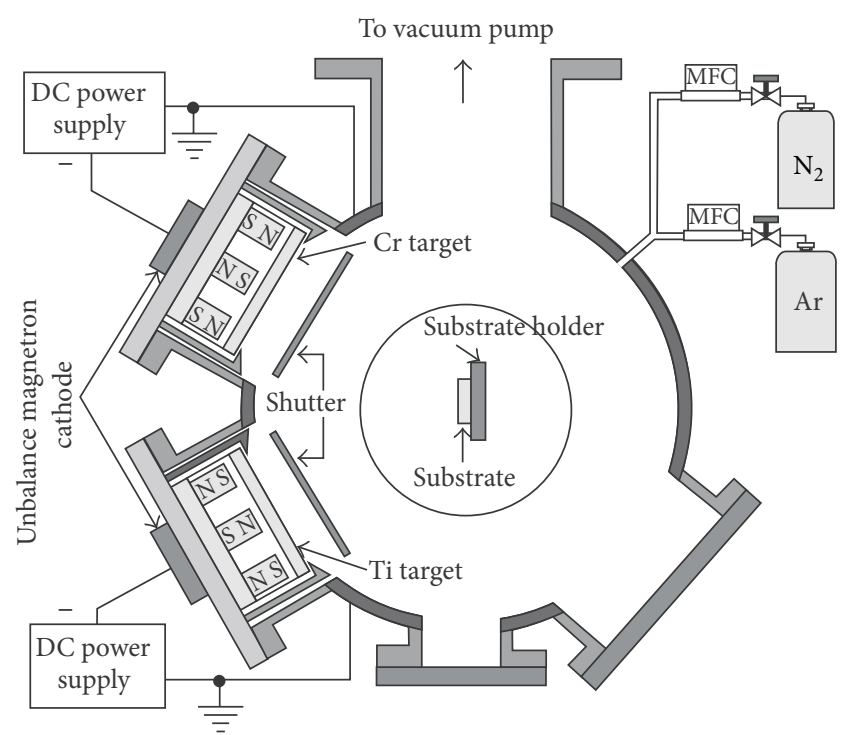

FIGURE 1: Schematic diagram of DC unbalanced magnetron cosputtering system.

TABle 1: Deposition conditions for TiCrN films.

\begin{tabular}{lc}
\hline Parameters & Details \\
\hline Base pressure (mbar) & $5 \times 10^{-5}$ \\
Working pressure (mbar) & $4 \times 10^{-5}$ \\
Ar flow rate $(\mathrm{sccm})$ & 3.0 \\
$\mathrm{~N}_{2}$ flow rate $(\mathrm{sccm})$ & 6.0 \\
Cr sputtering current, $I_{\mathrm{Cr}}(\mathrm{A})$ & 0.6 \\
Ti sputtering current, $I_{\mathrm{Ti}}(\mathrm{A})$ & $0.4,0.6,0.8$, and 1.0 \\
Deposition time $(\mathrm{min})$ & 60 \\
\hline
\end{tabular}

microscopy (AFM: Veeco, Nanoscope IV) and field emission scanning electron microscopy (FE-SEM: Hitachi, S4700), respectively.

\section{Results and Discussion}

3.1. Chemical Composition. The elemental composition of the TiCrN films was investigated by XPS as summarized in Table 2. As seen in Table 2, it also shows the Ti content and $\mathrm{N}$ content defined as $x=\mathrm{Ti} /(\mathrm{Ti}+\mathrm{Cr})$ and $y=\mathrm{N} /(\mathrm{Ti}+\mathrm{Cr})$ and film composition $\left(\mathrm{Ti}_{x} \mathrm{Cr}_{1-x} \mathrm{~N}_{y}\right)$ as a function of $I_{\mathrm{Ti}}$. It was observed that the Ti content increased from 0.10 to 0.37 when the $I_{\mathrm{Ti}}$ was increased from 0.4 to $1.0 \mathrm{~A}$. In addition, the $\mathrm{N}$ content in all the films also increased with increasing $I_{\mathrm{Ti}}$ even though the $\mathrm{N}_{2}$ flow rate was kept constant at $6.0 \mathrm{sccm}$. This result may be explained by the fact that the $\mathrm{N}$ affinity of $\mathrm{Ti}$ is higher than that of $\mathrm{Cr}$ atom $\left(\Delta \mathrm{H}_{\mathrm{TiN}}=-337.65 \mathrm{~kJ} / \mathrm{mol}\right.$, $\left.\Delta \mathrm{H}_{\mathrm{CrN}}=-117.15 \mathrm{~kJ} / \mathrm{mol}[21]\right)$ that led to more incorporation of $\mathrm{N}$ atom in the films [22]. The ratio of nitrogen to metals (y) was less than 1 revealing that all of the films were small understoichiometry which could be attributed to the effect of $\mathrm{Ar}^{+}$bombardment on preferential removal of nitrogen by surface cleaning process before XPS analysis [23]. The results 


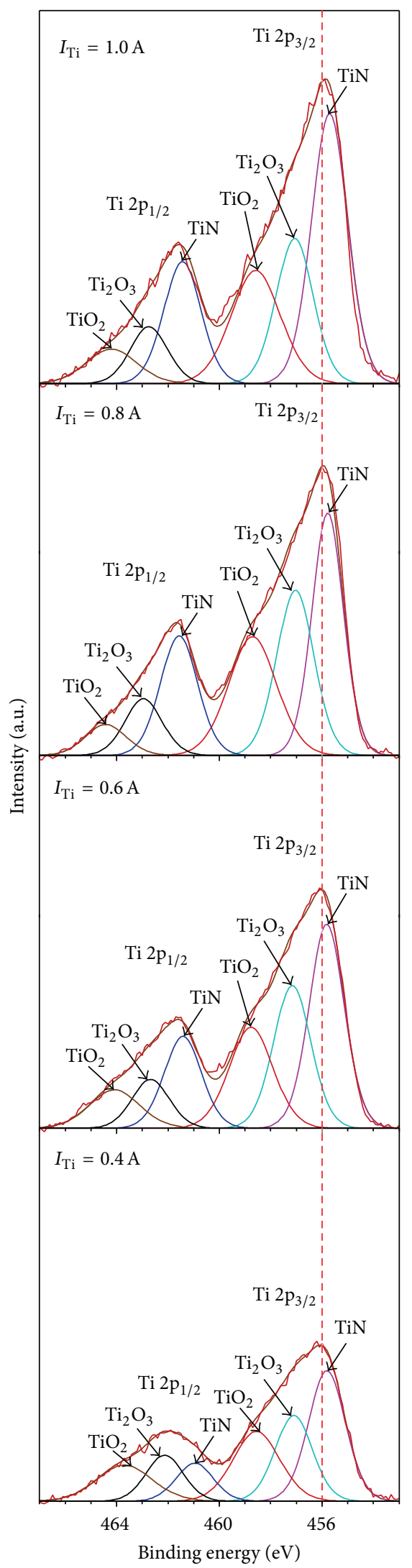

(a)

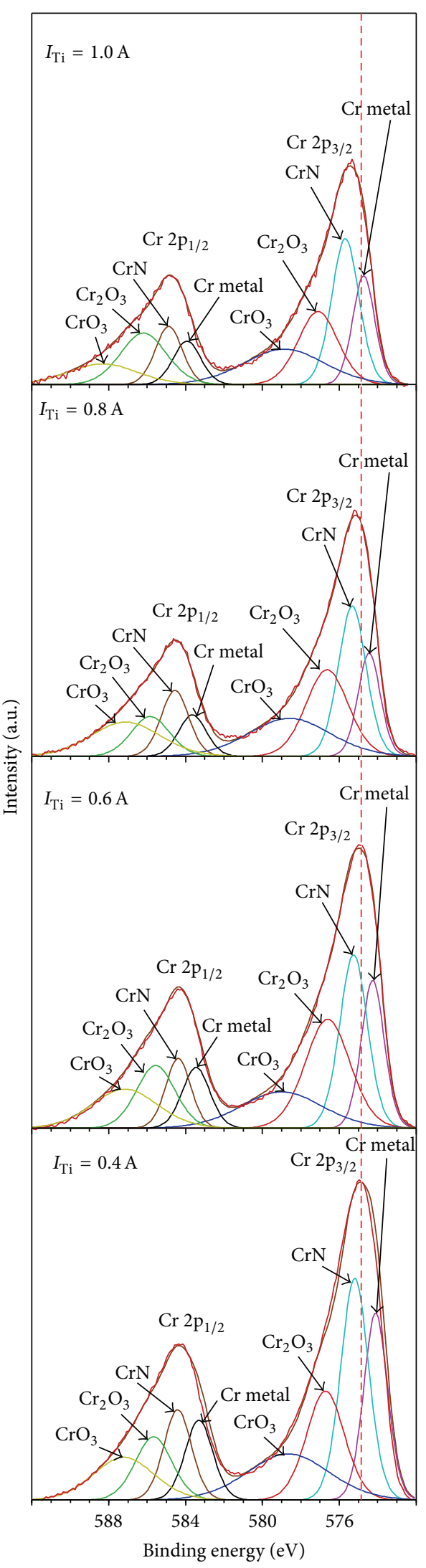

(b)

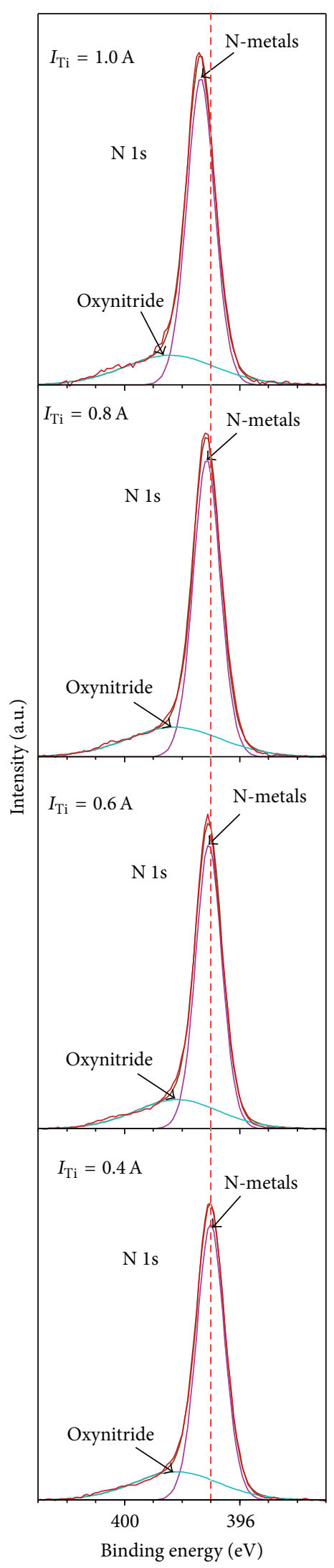

(c)

FIgURE 2: XPS deconvoluted spectra of (a) Ti 2p, (b) Cr 2p, and (c) N 1s. 
TABle 2: Elemental composition, Ti content ( $x$ value), $\mathrm{N}$ content ( $y$ value), and film composition as a function of the Ti sputtering current.

\begin{tabular}{|c|c|c|c|c|c|c|c|}
\hline \multirow{2}{*}{$I_{\mathrm{Ti}}(\mathrm{A})$} & \multicolumn{4}{|c|}{ Elemental composition (at. \%) } & \multirow{2}{*}{$x=\mathrm{Ti} /(\mathrm{Ti}+\mathrm{Cr})$} & \multirow{2}{*}{$y=\mathrm{N} /(\mathrm{Ti}+\mathrm{Cr})$} & \multirow{2}{*}{$\begin{array}{l}\text { Film composition } \\
\qquad\left(\mathrm{Ti}_{x} \mathrm{Cr}_{1-x} \mathrm{~N}_{y}\right)\end{array}$} \\
\hline & $\mathrm{Ti}$ & $\mathrm{Cr}$ & $\mathrm{N}$ & $\mathrm{O}$ & & & \\
\hline 0.4 & 4.72 & 42.98 & 34.78 & 17.52 & 0.10 & 0.73 & $\mathrm{Ti}_{0.10} \mathrm{Cr}_{0.90} \mathrm{~N}_{0.73}$ \\
\hline 0.6 & 10.04 & 35.74 & 37.30 & 16.92 & 0.22 & 0.81 & $\mathrm{Ti}_{0.22} \mathrm{Cr}_{0.78} \mathrm{~N}_{0.81}$ \\
\hline 0.8 & 16.29 & 30.55 & 38.29 & 14.87 & 0.35 & 0.82 & $\mathrm{Ti}_{0.33} \mathrm{Cr}_{0.65} \mathrm{~N}_{0.82}$ \\
\hline 1.0 & 17.60 & 29.58 & 39.07 & 13.75 & 0.37 & 0.83 & $\mathrm{Ti}_{0.37} \mathrm{Cr}_{0.63} \mathrm{~N}_{0.83}$ \\
\hline
\end{tabular}

also show the oxygen content about $14-17$ at.\% in the films that is probably due to the films exposure to the air ambient.

3.2. Chemical State. Figure 2 shows the evolution of the Ti $2 p$, $\mathrm{Cr} 2 \mathrm{p}$, and $\mathrm{N}$ 1s XPS core level spectra of the TiCrN films as a function of $I_{\mathrm{Ti}}$. The curves were fitted by Gaussian-Lorentzian function after performing Shirley background subtraction. The results showed that the intensity of the Ti and $\mathrm{N}$ peaks increased, whereas the Cr peak decreased with increasing $I_{\mathrm{Ti}}$ that corresponded to the elemental composition as shown in Table 2.

As shown in Figure 2, the deconvolution of Ti 2p spectrum showed that it is composed of three components that could be attributed to the chemical state of $\mathrm{TiN}, \mathrm{Ti}_{2} \mathrm{O}_{3}$, and $\mathrm{TiO}_{2}$. It should be noted that the intensity of TiN state increased with the increase of $\mathrm{Ti}$ and $\mathrm{N}$ concentrations. The deconvoluted $\mathrm{Cr} 2 \mathrm{p}$ spectrum indicated that it consisted of $\mathrm{Cr}$ metal, $\mathrm{CrN}, \mathrm{Cr}_{2} \mathrm{O}_{3}$, and $\mathrm{CrO}_{3}$ in which their intensities were decreased with increasing $I_{\mathrm{Ti}}$. The $\mathrm{N}$ 1s spectrum could be deconvoluted into two states, including metals nitride and oxynitride. These peaks were compared with XPS database compiled by National Institute of Standards and Technology (NIST) [24].

The binding energy $\left(E_{B}\right)$ of Ti peaks did not significantly change but tended to form more TiN, while that of the $\mathrm{Cr}$ peaks slightly shifted toward the higher $E_{B}$ from $574.9 \mathrm{eV}$ up to $575.3 \mathrm{eV}$ as the $I_{\mathrm{Ti}}$ increased. It could be attributed to the fact that there was a change in the chemical state from $\mathrm{Cr}$ metal to CrN as shown in Figure 2(b). In addition, the $E_{B}$ of $\mathrm{N}$ peaks also showed small shifts to the higher energy with increasing $I_{\mathrm{Ti}}$. This peak shift is due to the increase in the number of Ti atoms in CrN lattice when Ti content increased. Due to the fact that $\mathrm{Ti}$ atom has less valence electron than $\mathrm{Cr}$ atom, hence the substitution of $\mathrm{Ti}$ atoms for $\mathrm{Cr}$ atoms in CrN lattice leads to a decrease in electron density. Therefore, the Coulomb force exerted on these electrons by nucleus is stronger and results in an increase in $E_{B}$ of $\mathrm{N}$ core level $[25,26]$. The $E_{B}$ of $\mathrm{Ti} 2 \mathrm{p}_{3 / 2}, \operatorname{Cr} 2 \mathrm{p}_{3 / 2}$, and $\mathrm{N} 1$ s peaks was also presented in Table 3.

Furthermore, Table 4 showed the percentage of bond fraction contributing to XPS spectra which could be determined by using the area under the component peaks. The plots between the bond fraction and Ti sputtering current are also shown in Figure 3. The results showed that the bond fraction of $\mathrm{Ti}-\mathrm{N}$ increased with increasing $I_{\mathrm{Ti}}$ while that of $\mathrm{Cr}-\mathrm{N}$ slightly decreased. This result was owing to the increasing of $\mathrm{Ti}$ atoms in $\mathrm{CrN}$ structure that led to more bonding between $\mathrm{Ti}$ and $\mathrm{N}$ atoms. The results also exhibited

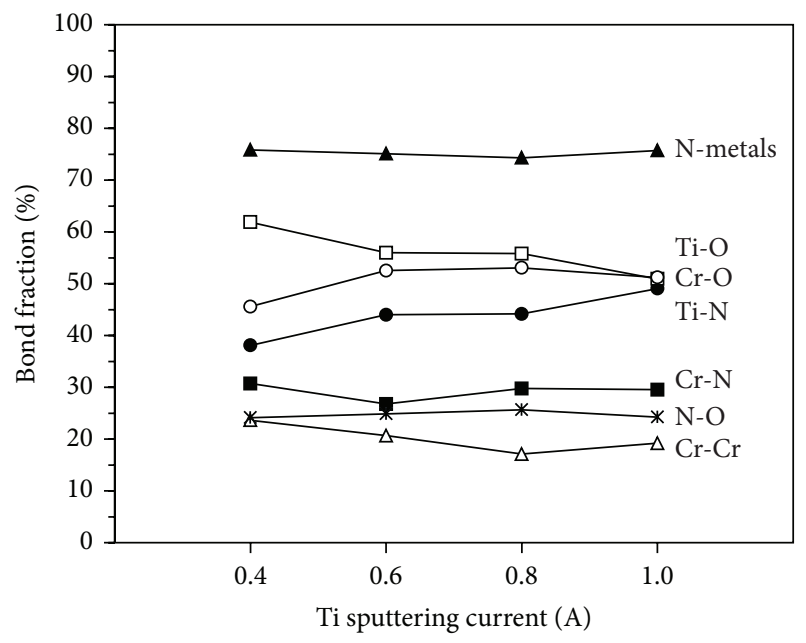

FIgURE 3: Relative bond fraction as a function of the Ti sputtering current.

TABLE 3: Binding energies of Ti $2 p_{3 / 2}, \operatorname{Cr} 2 p_{3 / 2}$, and $\mathrm{N}$ 1s peaks of the TiCrN films.

\begin{tabular}{lccc}
\hline$I_{\mathrm{Ti}}(\mathrm{A})$ & \multicolumn{3}{c}{ Binding energy $(\mathrm{eV})$} \\
\hline 0.4 & $\mathrm{Ti} 2 \mathrm{p}_{3 / 2}$ & $\mathrm{Cr} 2 \mathrm{p}_{3 / 2}$ & $\mathrm{~N} 1 \mathrm{~s}$ \\
0.6 & 456.0 & 574.9 & 397.0 \\
0.8 & 456.1 & 575.0 & 397.1 \\
1.0 & 456.0 & 575.2 & 397.2 \\
\hline
\end{tabular}

that the bond fractions of $\mathrm{N}$-metals according to each $I_{\mathrm{Ti}}$ are around $75 \%$.

3.3. Electronic Structure. The XPS valence band spectra are used to study the electronic structure of the TiCrN films as shown in Figure 4 . We observed that there were three dominant peaks located at $17,6.2$, and $1.6 \mathrm{eV}$ which were attributed to the $\mathrm{N} 2 \mathrm{~s}$ states, $\mathrm{N} 2 \mathrm{p}$ hybridized with Ti $3 \mathrm{~d} / \mathrm{Cr}$ $3 \mathrm{~d}$ states, and metallic $\mathrm{Ti} 3 \mathrm{~d} / \mathrm{Cr} 3 \mathrm{~d}$ states, respectively [9]. The valence electrons will occupy in the $\mathrm{N} 2$ s states and hybridized $\mathrm{N} 2 \mathrm{p}-\mathrm{Ti} 3 \mathrm{~d} / \mathrm{Cr} 3 \mathrm{~d}$ states by 2 and 6 electrons, respectively, whilst the extra electrons will fill in the metallic Ti $3 \mathrm{~d} / \mathrm{Cr} 3 \mathrm{~d}$ states [27]. It could be also noticed that the intensity of the $\mathrm{N} 2$ s states and N 2p-Ti 3d/Cr 3d states did not significantly change, while that of the metallic $\mathrm{Ti} 3 \mathrm{~d} / \mathrm{Cr} 3 \mathrm{~d}$ states gradually decreased with increasing $I_{\mathrm{Ti}}$. The results could be attributed to the fact that $\mathrm{Ti}$ atom has two valence electrons less than 
TABLE 4: The percentage of bond fraction contributing to Ti $2 \mathrm{p}_{3 / 2}$, Ti $2 \mathrm{p}_{1 / 2}, \operatorname{Cr} 2 \mathrm{p}_{3 / 2}, \operatorname{Cr} 2 \mathrm{p}_{1 / 2}$, and N $1 \mathrm{~s}$.

\begin{tabular}{|c|c|c|c|c|c|c|}
\hline \multirow{2}{*}{$I_{\mathrm{Ti}}(\mathrm{A})$} & \multicolumn{2}{|c|}{$\operatorname{Ti} 2 \mathrm{p}_{3 / 2}+\operatorname{Ti} 2 \mathrm{p}_{1 / 2}$} & \multicolumn{2}{|c|}{$\operatorname{Cr} 2 \mathrm{p}_{3 / 2}+\operatorname{Cr} 2 \mathrm{p}_{1 / 2}$} & \multicolumn{2}{|c|}{$\mathrm{N} 1 \mathrm{~s}$} \\
\hline & Bond assigned & Bond fraction (\%) & Bond assigned & Bond fraction (\%) & Bond assigned & Bond fraction (\%) \\
\hline \multirow{3}{*}{0.4} & $\mathrm{Ti}-\mathrm{N}$ & 38.11 & $\mathrm{Cr}-\mathrm{Cr}$ & 23.66 & N-metals & 75.84 \\
\hline & $\mathrm{Ti}-\mathrm{O}$ & 61.89 & $\mathrm{Cr}-\mathrm{N}$ & 30.74 & $\mathrm{~N}-\mathrm{O}$ & 24.16 \\
\hline & & & $\mathrm{Cr}-\mathrm{O}$ & 45.60 & & \\
\hline \multirow{3}{*}{0.6} & $\mathrm{Ti}-\mathrm{N}$ & 44.00 & $\mathrm{Cr}-\mathrm{Cr}$ & 20.68 & N-metals & 75.11 \\
\hline & $\mathrm{Ti}-\mathrm{O}$ & 56.00 & $\mathrm{Cr}-\mathrm{N}$ & 26.78 & $\mathrm{~N}-\mathrm{O}$ & 24.89 \\
\hline & & & $\mathrm{Cr}-\mathrm{O}$ & 52.54 & & \\
\hline \multirow{3}{*}{0.8} & $\mathrm{Ti}-\mathrm{N}$ & 44.18 & $\mathrm{Cr}-\mathrm{Cr}$ & 17.13 & N-metals & 74.32 \\
\hline & $\mathrm{Ti}-\mathrm{O}$ & 55.82 & $\mathrm{Cr}-\mathrm{N}$ & 29.79 & $\mathrm{~N}-\mathrm{O}$ & 25.68 \\
\hline & & & $\mathrm{Cr}-\mathrm{O}$ & 53.08 & & \\
\hline \multirow{3}{*}{1.0} & $\mathrm{Ti}-\mathrm{N}$ & 49.08 & $\mathrm{Cr}-\mathrm{Cr}$ & 19.23 & N-metals & 75.73 \\
\hline & $\mathrm{Ti}-\mathrm{O}$ & 50.92 & $\mathrm{Cr}-\mathrm{N}$ & 29.55 & $\mathrm{~N}-\mathrm{O}$ & 24.27 \\
\hline & & & $\mathrm{Cr}-\mathrm{O}$ & 51.22 & & \\
\hline
\end{tabular}

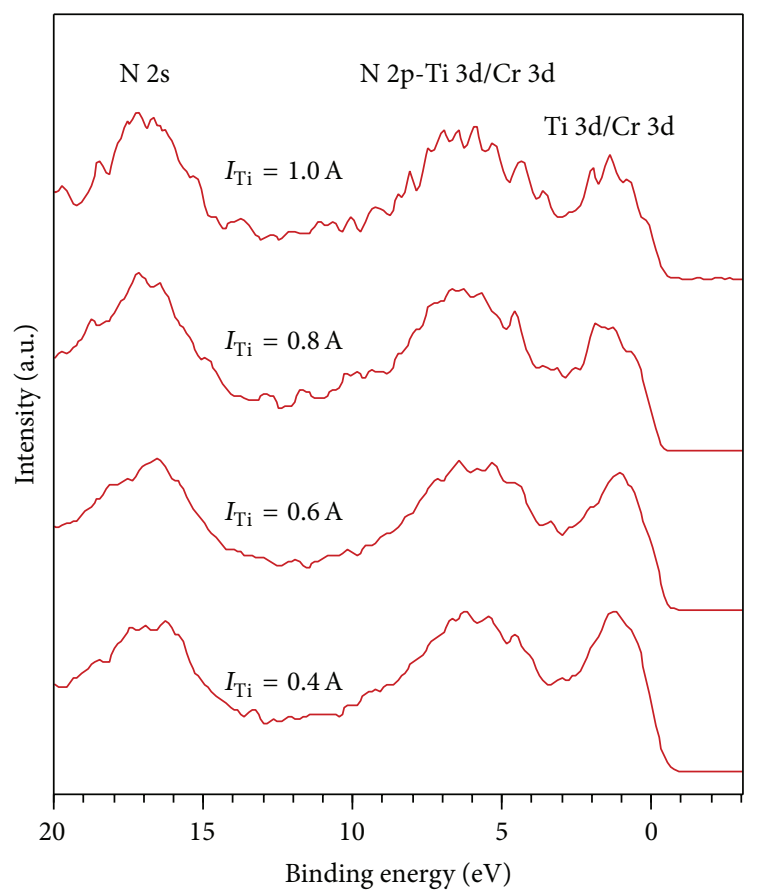

FIGURE 4: XPS valence band spectra of the TiCrN films at various $\mathrm{Ti}$ sputtering currents.

Cr atom that led to the decrease of valence electrons in the $\mathrm{d}$ conduction bands. This also confirmed the peak shift results of binding energy in the chemical state section as described above.

3.4. Structural Analysis. The X-ray diffraction patterns of TiCrN films as a function of $I_{\mathrm{Ti}}$ are shown in Figure 5. The results revealed that $\mathrm{TiCrN}$ films exhibited crystalline structure with fcc B1 type phase and (111), (200), and (220) peaks were also found. These peaks were between TiN and CrN positions according to JCPDS files numbers 87-0633 and 77-0047, respectively. All films show strong (111) preferred

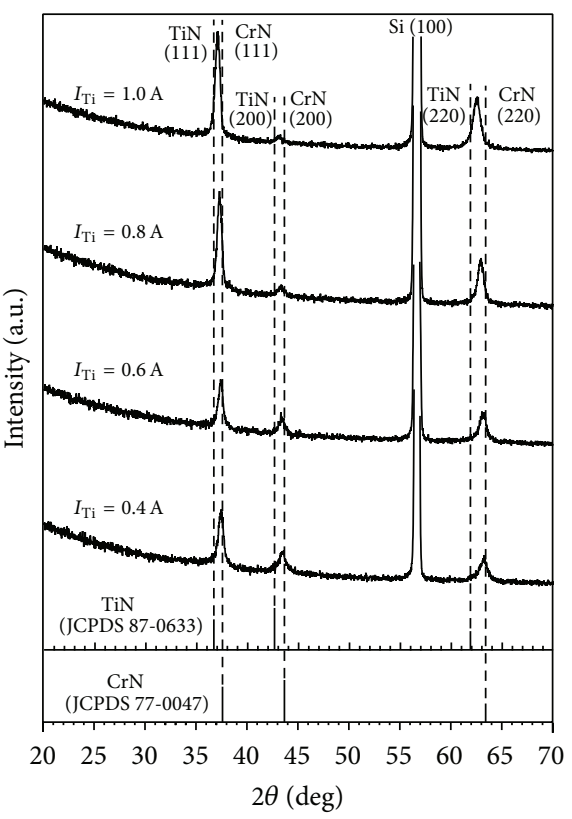

FIgURE 5: XRD patterns of the TiCrN films deposited at various Ti sputtering currents.

orientation, which is the lowest strain energy plane of fcc B1 type structure [28]. It was also noticed that the (111) peak intensity of XRD patterns increased with increasing $I_{\mathrm{Ti}}$. This result could be attributed to the increasing of film thickness and the higher energy of ion bombardment which resulted in an increase in crystallinity of the films [22].

Moreover, as the $I_{\mathrm{Ti}}$ increased, the peak positions shifted toward the lower diffraction angles. It suggested that the films were formed as $(\mathrm{Ti}, \mathrm{Cr}) \mathrm{N}$ solid solution whereby $\mathrm{Cr}$ atoms were substituted by Ti atoms within the $\mathrm{CrN}$ structure. Due to the fact that the atomic radius of $\mathrm{Ti}(0.1445 \mathrm{~nm})$ is bigger than that of $\mathrm{Cr}(0.1249 \mathrm{~nm})$ [29], therefore, the lattice parameter (a) of the TiCrN films increased with increasing $I_{\mathrm{Ti}}$ as shown in Figure 6. 


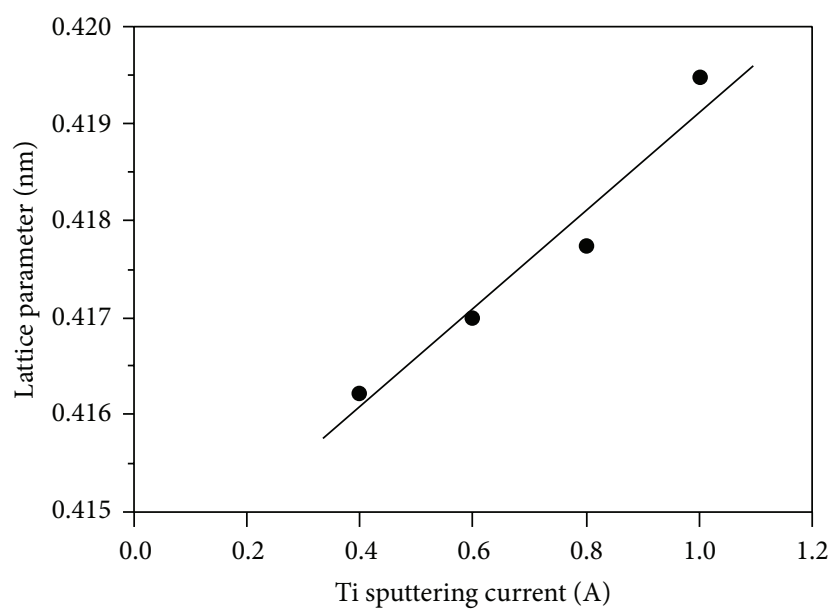

FIgURE 6: Lattice parameter of the TiCrN films as a function of the Ti sputtering current.

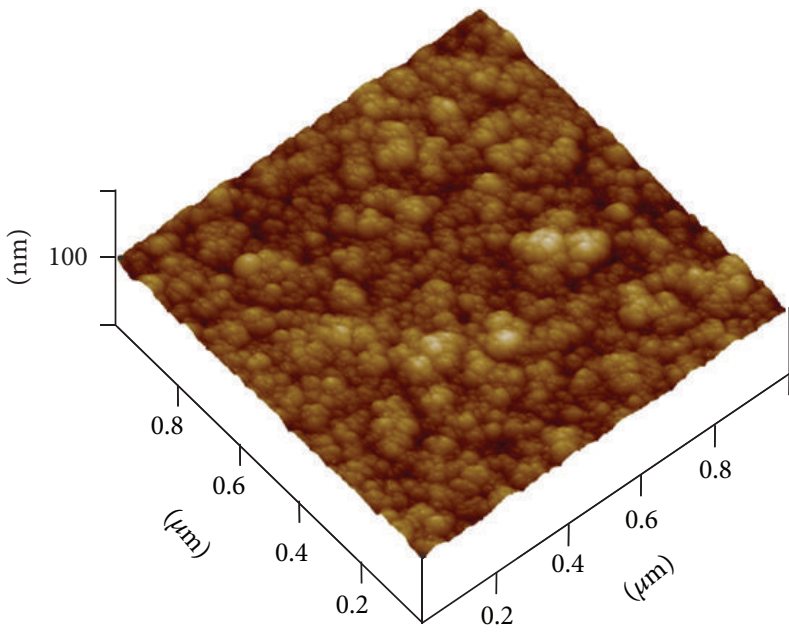

(a)

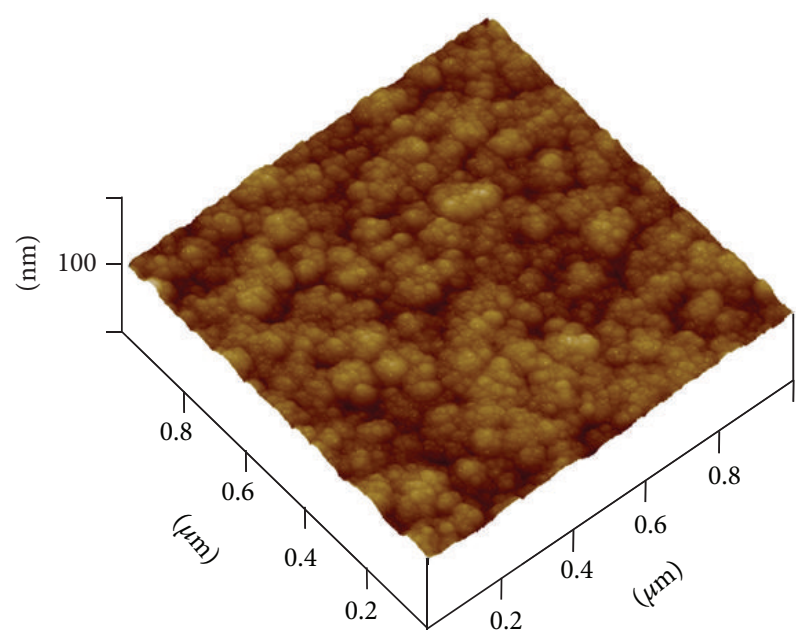

(c)

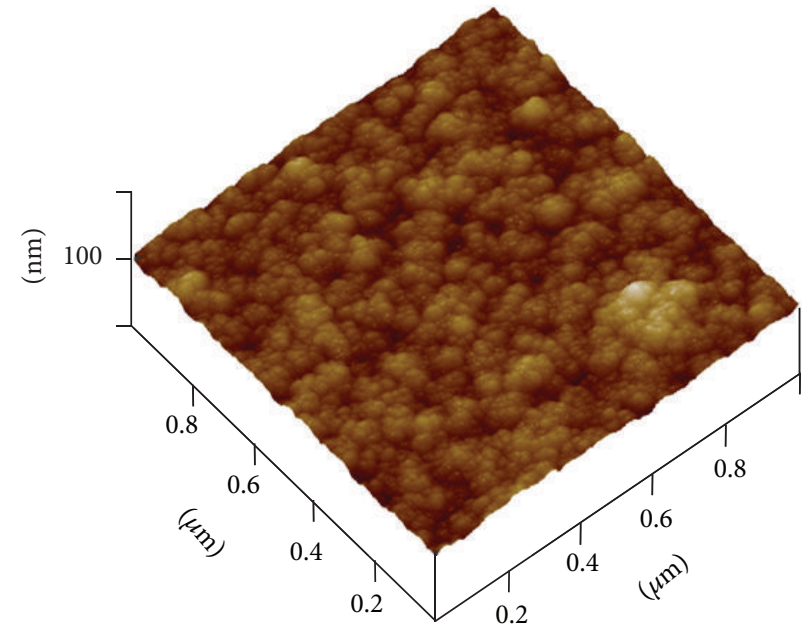

(b)

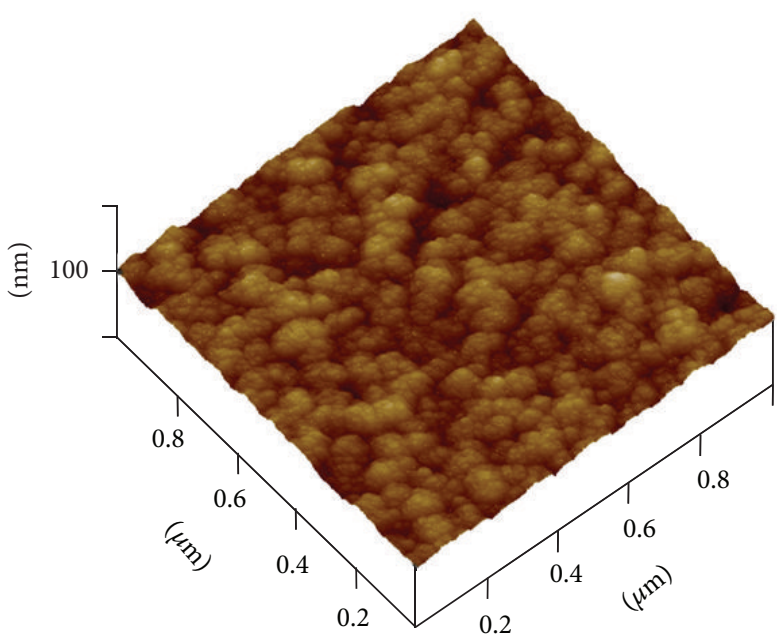

(d)

Figure 7: AFM images of the TiCrN films deposited at various Ti sputtering currents of (a) 0.4, (b) 0.6, (c) 0.8 , and (d) 1.0 A. 


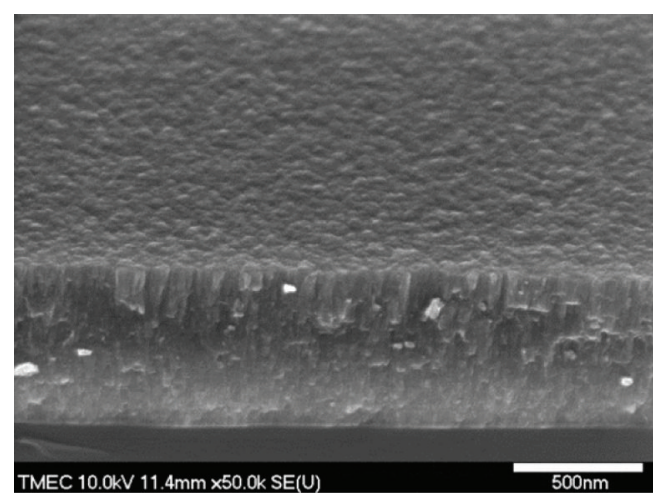

(a)

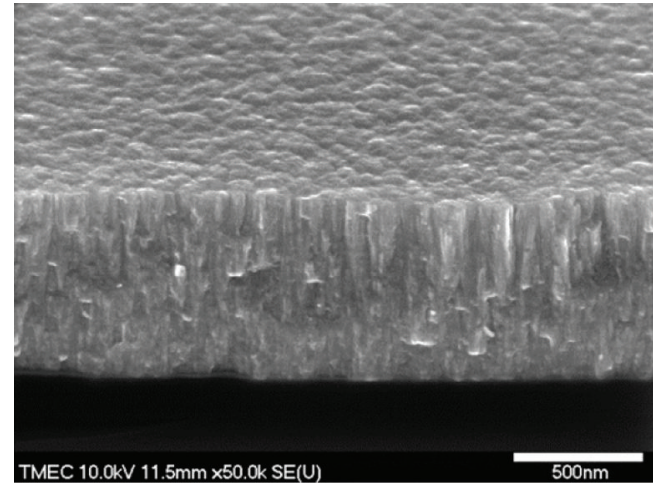

(c)

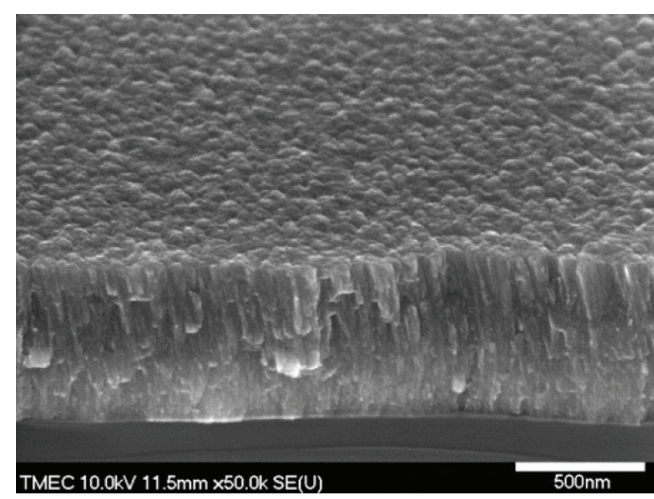

(b)

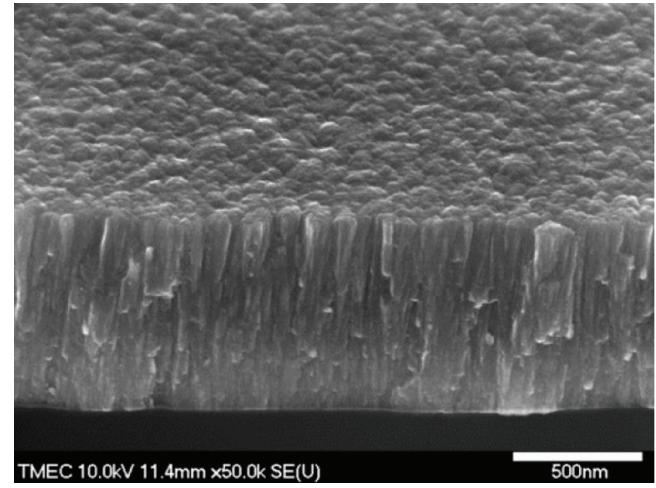

(d)

FIGURE 8: Cross-sectional FE-SEM morphology of the TiCrN films deposited at various Ti sputtering currents of (a) 0.4 , (b) 0.6 , (c) 0.8 , and (d) $1.0 \mathrm{~A}$.

The crystallite sizes of the films $(t)$, which were calculated from (111) peak using Scherrer's formula, were found to have values of about $12-13 \mathrm{~nm}$. This result confirmed that the TiCrN films formed nanostructured film.

\subsection{Surface and Cross-Sectional Morphologies. The AFM sur-} face images of the TiCrN films as a function of Ti sputtering current are shown in Figure 7. It was found that the films have rough surfaces and dome top characteristic resulting from the atomic shadowing and limited adatom surface diffusion [30]. However, it is seen that the surface morphologies of all the films deposited at various $\mathrm{Ti}$ sputtering currents are not significantly different. As the $I_{\mathrm{Ti}}$ increased from 0.4 to $1.0 \mathrm{~A}$, the root-mean-square roughness $\left(R_{\mathrm{rms}}\right)$ slightly increased from 3.041 to $3.941 \mathrm{~nm}$ in accordance with the increasing of film thickness as shown in Table 5.

The cross-sectional morphology of the TiCrN films with different conditions of Ti sputtering current was examined by FE-SEM as shown in Figure 8 . The results revealed that these films showed columnar structure with dome tops at the surfaces, which corresponded to zone 1 according to the Thornton's structure zone model (SZM) [31], and were consistent with the AFM results. In addition, the columns width gradually increased and resulted in dome size slightly increased with film thickness. As the $I_{\mathrm{Ti}}$ increased, the thickness of the films was found to increase from 726 to
TABLE 5: Roughness and thickness of the TiCrN films as a function of Ti sputtering current.

\begin{tabular}{lcc}
\hline$I_{\mathrm{Ti}}(\mathrm{A})$ & Roughness $(\mathrm{nm})$ & Thickness $(\mathrm{nm})$ \\
\hline 0.4 & 3.041 & 726 \\
0.6 & 3.527 & 774 \\
0.8 & 3.732 & 876 \\
1.0 & 3.941 & 916 \\
\hline
\end{tabular}

$916 \mathrm{~nm}$ as shown in Table 5. These results are in accordance with XRD results as discussed in previous section.

\section{Conclusions}

Nanostructured TiCrN films were deposited by DC unbalanced magnetron cosputtering technique without external heating and biasing to the substrates. The effects of the $\mathrm{Ti}$ sputtering current on the chemical state, electronic structure, crystal structure, and morphology of the films were investigated. The XPS results showed that the films were small understoichiometry. The deconvoluted XPS spectra of Ti 2p, $\mathrm{Cr} 2 \mathrm{p}$, and $\mathrm{N}$ 1s revealed the chemical states of metals nitride, metals oxide, and oxynitride. The oxidation was owing to the films surfaces exposed to the air ambient. The XPS valence band spectra demonstrated the change in intensity of 
the metallic $\mathrm{Ti} 3 \mathrm{~d} / \mathrm{Cr} 3 \mathrm{~d}$ states resulting from the decrease of valence electrons in d conduction bands when the Ti content increased. This also affected the binding energy of electrons in core level. XRD results exhibited that the films formed a solid solution with fcc Bl type phase and crystallite sizes were less than $14 \mathrm{~nm}$. AFM images showed the roughness of the film surfaces resulting from the atomic shadowing and limited adatom diffusion. FE-SEM images showed columnar structure corresponding to zone 1 .

\section{Conflict of Interests}

The authors declare that there is no conflict of interests regarding the publication of this paper.

\section{Acknowledgments}

The authors are grateful for the grant supported by the Thai Government Science and Technology Scholarship. They would like to thank Vacuum Technology and Thin Films Research Laboratory, Burapha University, for providing the sputtering system, and Dr. A. Buranawong for assistance with XRD measurement. This research is supported by King Mongkut's University of Technology Thonburi (KMUTT) under the National Research University project and Thailand Center of Excellence in Physics.

\section{References}

[1] P. Roquiny, F. Bodart, and G. Terwagne, "Colour control of titanium nitride coatings produced by reactive magnetron sputtering at temperature less than $100 \circ \mathrm{C}$," Surface and Coatings Technology, vol. 116-119, pp. 278-283, 1999.

[2] Y. Shi, S. Long, L. Fang, F. Pan, and H. Liao, "Effects of $\mathrm{N}_{2}$ content and thickness on $\mathrm{CrN}_{x}$ coatings on $\mathrm{Mg}$ alloy by the planar DC reactive magnetron sputtering," Applied Surface Science, vol. 255, no. 13-14, pp. 6515-6524, 2009.

[3] A. Rizzo, M. A. Signore, L. Mirenghi, and E. Serra, "Properties of $\mathrm{ZrN}_{x}$ films with $\mathrm{x}>1$ deposited by reactive radiofrequency magnetron sputtering," Thin Solid Films, vol. 515, no. 4, pp.13071313, 2006.

[4] B. Navinšek, P. Panjan, and A. Cvelbar, "Characterization of low temperature CrN and TiN (PVD) hard coatings," Surface and Coatings Technology, vol. 74-75, no. 1, pp. 155-161, 1995.

[5] H. S. Choi, D. H. Han, W. H. Hong, and J. J. Lee, "(Titanium, chromium) nitride coatings for bipolar plate of polymer electrolyte membrane fuel cell," Journal of Power Sources, vol. 189, no. 2, pp. 966-971, 2009.

[6] D. H. Jung, H. S. Park, H. D. Na, J. W. Lim, J. J. Lee, and J. H. Joo, "Mechanical properties of $(\mathrm{Ti}, \mathrm{Cr}) \mathrm{N}$ coatings deposited by inductively coupled plasma assisted direct current magnetron sputtering," Surface and Coatings Technology, vol. 169-170, pp. 424-427, 2003.

[7] J. G. Han, H. S. Myung, H. M. Lee, and L. R. Shaginyan, "Microstructure and mechanical properties of Ti-Ag-N and TiCr-N superhard nanostructured coatings," Surface \& Coatings Technology, vol. 174-175, pp. 738-743, 2003.

[8] J. H. Hsieh, W. H. Zhang, C. Li, and C. Q. Sun, "Characterization of $\left(\mathrm{Ti}_{x} \mathrm{Cr}_{0.6-x}\right) \mathrm{N}_{0.4}$ coatings and their tribological behaviors against an epoxy molding compound," Surface and Coatings Technology, vol. 146-147, pp. 331-337, 2001.

[9] P. Hones, R. Sanjinés, and F. Lévy, "Sputter deposited chromium nitride based ternary compounds for hard coatings," Thin Solid Films, vol. 332, no. 1-2, pp. 240-246, 1998.

[10] Y. Otani and S. Hofmann, "High temperature oxidation behaviour of $\left(\mathrm{Ti}_{1-x} \mathrm{Cr}_{x}\right) \mathrm{N}$ coatings," Thin Solid Films, vol. 287, no. 1-2, pp. 188-192, 1996.

[11] Z. G. Zhang, O. Rapaud, N. Bonasso, D. Mercs, C. Dong, and C. Coddet, "Microstructures and corrosion behaviors of $\mathrm{Zr}$ modified $\mathrm{CrN}$ coatings deposited by DC magnetron sputtering," Vacuum, vol. 82, no. 11, pp. 1332-1336, 2008.

[12] K. Chu, P. W. Shum, and Y. G. Shen, "Substrate bias effects on mechanical and tribological properties of substitutional solid solution ( $\mathrm{Ti}, \mathrm{Al}) \mathrm{N}$ films prepared by reactive magnetron sputtering," Materials Science and Engineering B, vol. 131, no. 13, pp. 62-71, 2006.

[13] L. Wang, G. Zhang, R. J. K. Wood, S. C. Wang, and Q. Xue, "Fabrication of CrAlN nanocomposite films with high hardness and excellent anti-wear performance for gear application," Surface and Coatings Technology, vol. 204, no. 21-22, pp. 35173524, 2010.

[14] D. B. Lee, Y. C. Lee, and S. C. Kwon, "High temperature oxidation of TiCrN coatings deposited on a steel substrate by ion plating," Surface and Coatings Technology, vol. 141, no. 2-3, pp. 232-239, 2001.

[15] S. M. Aouadi, K. C. Wong, K. A. R. Mitchell et al., "Characterization of titanium chromium nitride nanocomposite protective coatings," Applied Surface Science, vol. 229, no. 1-4, pp. 387-394, 2004.

[16] J. J. Nainaparampil, J. S. Zabinski, and A. Korenyi-Both, "Formation and characterization of multiphase film properties of (Ti-Cr)N formed by cathodic arc deposition," Thin Solid Films, vol. 333, no. 1-2, pp. 88-94, 1998.

[17] J. Vetter, H. J. Scholl, and O. Knotek, “(TiCr)N coatings deposited by cathodic vacuum arc evaporation," Surface and Coatings Technology, vol. 74-75, no. 1, pp. 286-291, 1995.

[18] K. H. Lee, C. H. Park, Y. S. Yoon, and J. J. Lee, "Structure and properties of $\left(\mathrm{Ti}_{1-x} \mathrm{Cr}_{x}\right) \mathrm{N}$ coatings produced by the ion-plating method," Thin Solid Films, vol. 385, no. 1-2, pp. 167-173, 2001.

[19] K. H. Lee, C. H. Park, Y. S. Yoon, H. A. Jehn, and J. J. Lee, "Wear and corrosion properties of $\left(\mathrm{Ti}_{1-x} \mathrm{Cr}_{x}\right) \mathrm{N}$ coatings produced by the ion-plating method," Surface and Coatings Technology, vol. 142-144, pp. 971-977, 2001.

[20] V. M. Vishnyakov, V. I. Bachurin, K. F. Minnebaev et al., "Ion assisted deposition of titanium chromium nitride," Thin Solid Films, vol. 497, no. 1-2, pp. 189-195, 2006.

[21] http://webbook.nist.gov.

[22] A. Cavaleiro, B. Trindade, and M. T. Vieira, "The influence of the addition of a third element on the structure and mechanical properties of transition-metal-based nanostructured hard films: part I-nitrides," in Nanostructured Coatings, A. Cavaleiro and J. T. M. de Hosson, Eds., Springer, New York, NY, USA, 2006.

[23] I. Bertóti, "Characterization of nitride coatings by XPS," Surface and Coatings Technology, vol. 151-152, pp. 194-203, 2002.

[24] http://srdata.nist.gov/xps/ElmComposition.aspx.

[25] P. van der Heide, X-Ray Photoelectron Spectroscopy: An Introduction to Principles and Practices, John Wiley \& Sons, Hoboken, NJ, USA, 2011.

[26] D. G. Sangiovanni, V. Chirita, and L. Hultman, "Electronic mechanism for toughness enhancement in $\mathrm{Ti}_{x} M_{1-x} \mathrm{~N}(M=$ Mo 
and W)," Physical Review B, vol. 81, no. 10, Article ID 104107, 2010.

[27] F. Tian, J. D’Arcy-Gall, T.-Y. Lee et al., "Epitaxial $\mathrm{Ti}_{1-x} \mathrm{~W}_{x} \mathrm{~N}$ alloys grown on $\mathrm{MgO}(001)$ by ultrahigh vacuum reactive magnetron sputtering: Electronic properties and long-range cation ordering," Journal of Vacuum Science and Technology A, vol. 21, no. 1, pp. 140-146, 2003.

[28] G. Kim, B. Kim, S. Lee, and J. Hahn, "Structure and mechanical properties of Cr-Zr-N films synthesized by closed field unbalanced magnetron sputtering with vertical magnetron sources," Surface and Coatings Technology, vol. 200, no. 5-6, pp. 1669$1675,2005$.

[29] W. D. Callister Jr. and D. G. Rethwisch, Material Science and Engineering: An Introduction, John Wiley \& Sons, Hoboken, NJ, USA, 8th edition, 2010.

[30] J. E. Greene, "Thin film nucleation, growth, and microstructural evolution: an atomic scale view," in Handbook of Deposition Technologies for Films and Coatings, P. M. Martin, Ed., William Andrew, New York, NY, USA, 3rd edition, 2010.

[31] D. M. Mattox, Handbook of Physical Vapor Deposition (PVD) Processing, William Andrew, Oxford, UK, 2nd edition, 2010. 

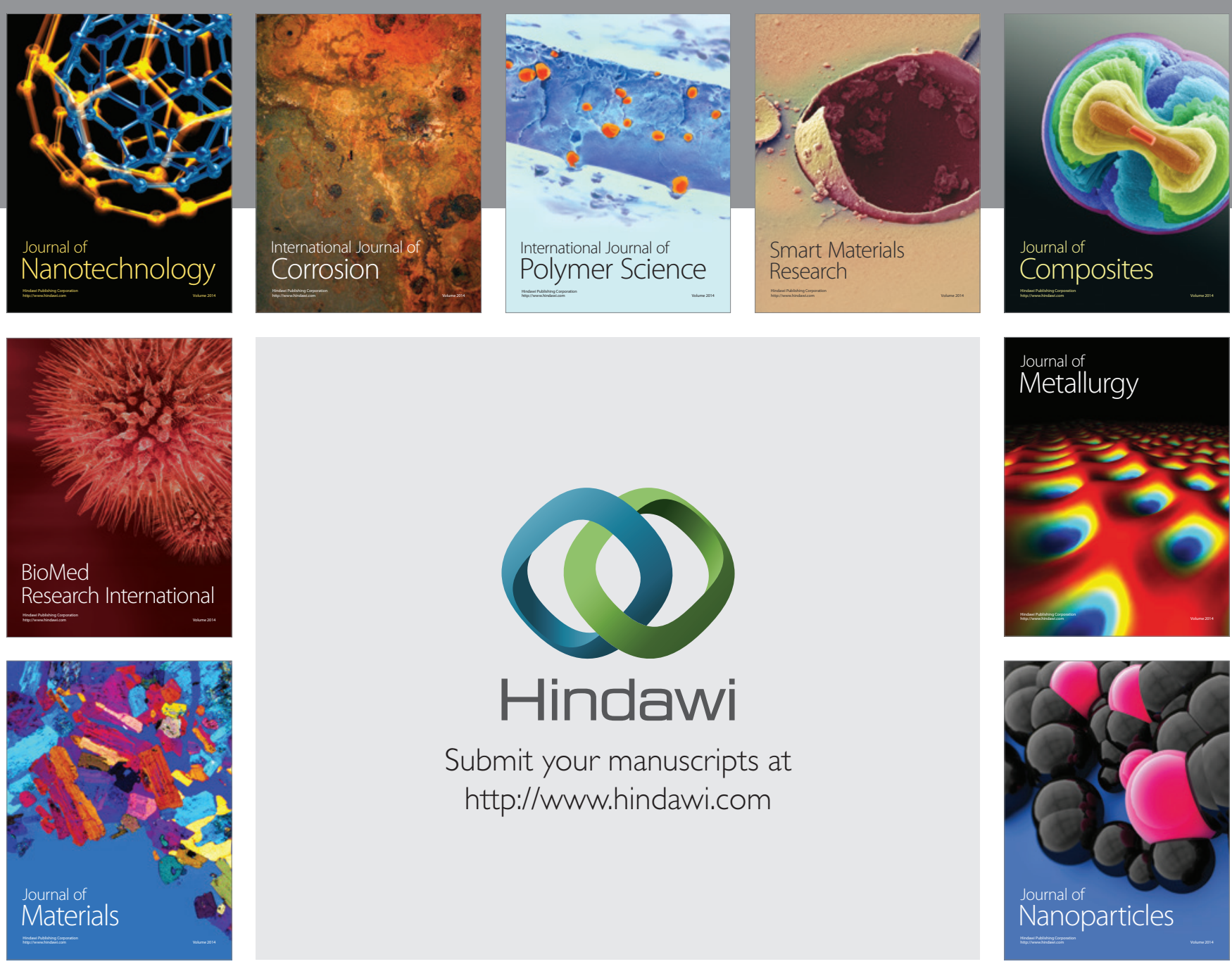

Submit your manuscripts at http://www.hindawi.com
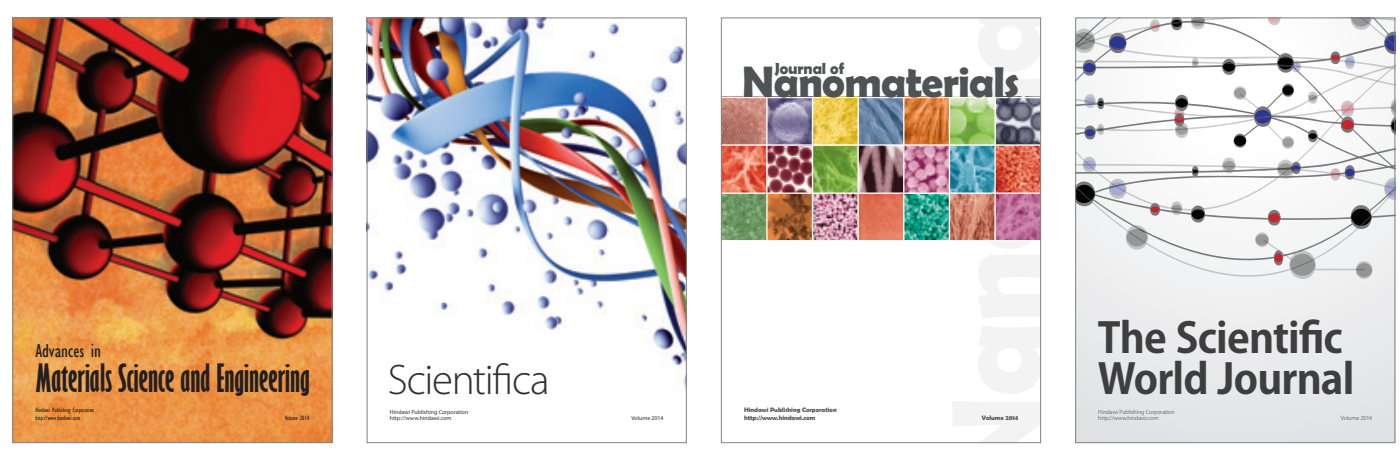

\section{The Scientific World Journal}
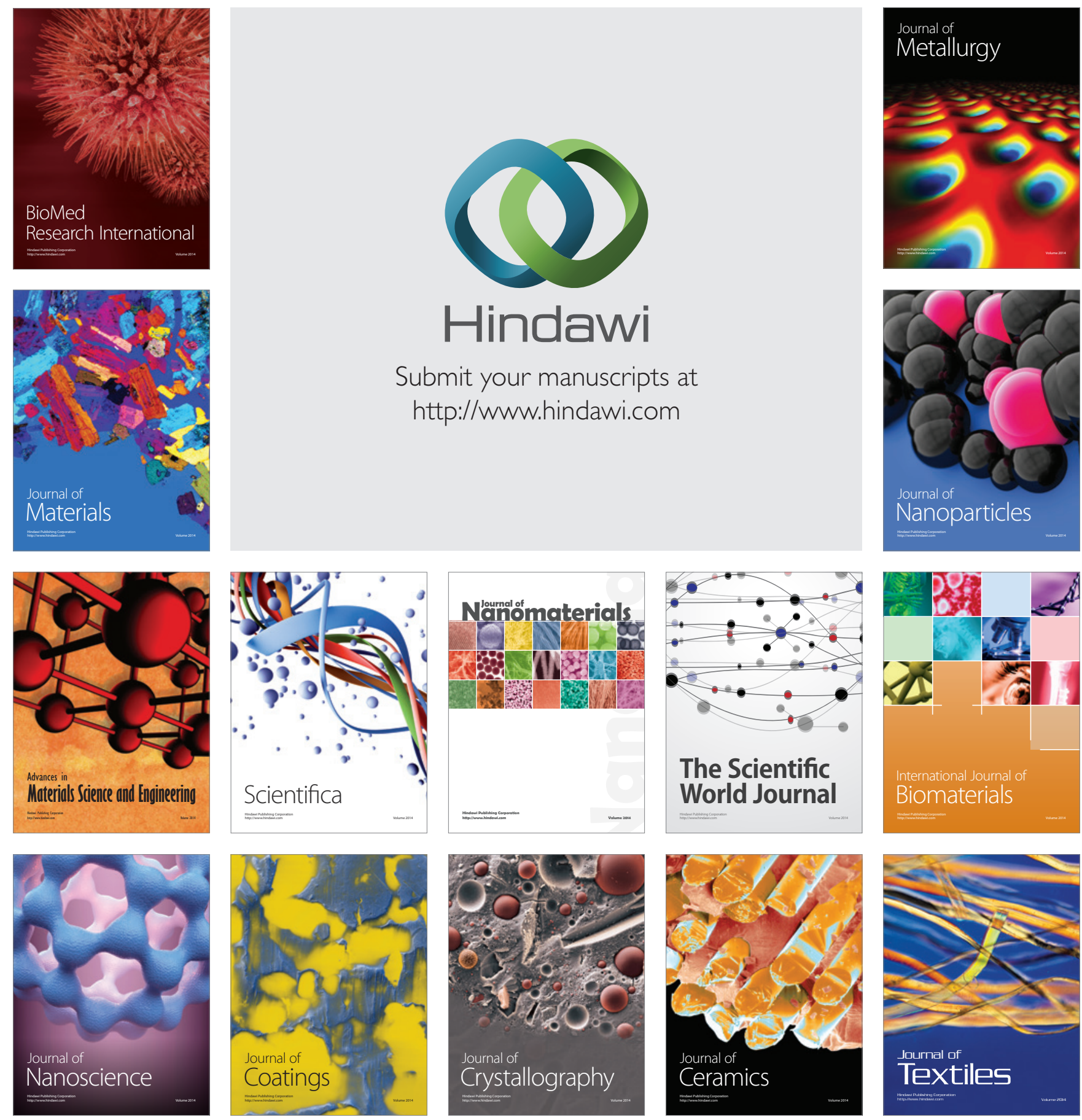